\title{
Ischemia and fibrosis: the risk mechanisms of hypertensive heart disease
}

E.D. Frohlich

\author{
Correspondence \\ E.D. Frohlich \\ Alton 0 chsner Medical Foundation \\ 1516 Jefferson Highway \\ New O rleans, LA 70121 \\ USA \\ Fax: + 1-504-842-3258
}

Presented at the III International Symposium on Vasoactive Peptides, Belo Horizonte, MG, Brasil, October 8-10, 1999.

Received November 26, 1999 Accepted February 2, 2000
Alton $\mathrm{O}$ chsner Medical Foundation, New O rleans, LA, USA

\begin{abstract}
Mechanisms underlying risk associated with hypertensive heart disease (HHD) and left ventricular hypertrophy (LVH) are discussed in this report and provide a rationale for understanding this very common and important cause of death from hypertension and its complications. Emphasized are impaired coronary hemodynamics, endothelial dysfunction, and ventricular fibrosis from increased collagen deposition intramurally and perivascularly. Each is exacerbated by aging and, perhaps, also by increased dietary salt intake. These functional and structural changes promote further endothelial dysfunction, altered coronary hemodynamics, and diastolic as well as systolic ventricular contractile function in HHD. The clinical endpoints of HHD include angina pectoris (with or without atherosclerosis of the epicardial coronary arteries), myocardial infarction, cardiac failure, lethal dysrhythmias, and sudden death. The major concept to be derived from these alterations is that not all that is clinically recognized as LVH is true myocytic hypertrophy and structural remodeling. Other major co-morbid changes occur that serve to increase cardiovascular risk including impaired coronary hemodynamics, endothelial dysfunction, and ventricular fibrosis.
\end{abstract}

\section{Earlier postulated mechanisms}

In previous reports, several mechanisms were proposed to explain potential risks associated with left ventricular hypertrophy (LVH) (1-3). Until recently, alterations associated with cardiac enlargement other than the hypertrophy were not considered although early reports suggested that "pathological" hypertrophy might be associated with altered myosin isozymes (4), and that LVH predisposed the ventricle to lethal arrhythmias $(5,6)$. Although sudden death is more common in patients with $\mathrm{LVH}$, the underlying mechanism(s) is not explained by this observation (7). At present, the most reasonable mechan- ism explaining risk associated with $\mathrm{LVH}$ is impaired coronary hemodynamics manifested by reduced coronary blood flow and flow reserve associated with increased coronary vascular resistance and minimal coronary resistance (8-10). Resting coronary hemodynamic parameters need not be impaired, however; but they may become deranged in otherwise asymptomatic individuals by certain physiological or pharmacological interventions (9-11), reflecting impaired coronary arteriolar dilation engendered by the coronary arteriolar constriction of hypertension, as well as by endothelial dysfunction (1214).

Endothelial dysfunction has been dem- 
onstrated clinically, as well as experimentally and relates to a defect in the local vascular and myocardial generation of nitric oxide (12-14). Additional hemodynamic mechanisms which may account for impaired coronary hemodynamics include coronary arteriolar compression by the hypertrophied and stiffer left ventricle (LV) produced by ventricular fibrosis, occlusive atherosclerotic epicardial coronary arterial disease that exacerbates the hypertensive disease, the increased arteriolar wall thickening and arteriolar wall-to-lumen diameter directly characteristic of hypertensive vascular disease (15), inadequate sizing of coronary vessels (16), increased blood viscosity in hypertension (17), and the increased LV chamber diameter reflecting not only myocytic hypertrophy but type 3 collagen deposition (18-20). This increased diameter and the elevated systolic pressure raises left ventricular wall tension and myocardial oxygen demand.

\section{Coronary heart disease}

It is appropriate to define what is meant by coronary heart disease (CHD) when one discusses the risk of LVH. Following publication of the first meta-analysis of the initial 14 multicenter controlled antihypertensive trials much controversy ensued resulting from misinterpretation of CHD. The report predicted that antihypertensive therapy would reduce deaths from stroke and CHD by 35-40 and $20-25 \%$, respectively (21). Indeed, highly significant reductions in stroke $(43 \%)$ and CHD (14\%) were demonstrated $(\mathrm{P}<0.01)$. However, the difference between the 25-30 predicted and the actual $14 \%$ reductions in CHD deaths precipitated much discussion suggesting that diuretics and beta-blockers failed to prevent deaths from myocardial infarction. This conclusion was erroneous: the studies were abruptly discontinued when significant reductions of deaths from stroke were demonstrated for ethical reasons and the deaths from CHD were not exclusively caused by myocardial infarction. These unfounded conclusions suggested that the antihypertensive drug classes employed raised serum lipid levels thereby exacerbated the atherosclerotic process, and the data failed to show a reduction in CHD deaths. These concerns can be countered by several facts: first, reduction of stroke deaths has always been shown before reduction of deaths from $\mathrm{CHD}$, suggesting that the cerebral circulation may be more rapidly amenable to pressure reduction than the coronary circulation. Secondly, whereas the antihypertensive therapy did not account for promotion of hyperlipidemia and exacerbated atherosclerosis, it could have promoted significant hypokalemia (vide infra). Finally, deaths from CHD did not exclusively result from myocardial infarction, and this means that the definition employed for CHD in these studies must be stated more clearly. Deaths attributable to CHD (as defined by the study epidemiologists) included more endpoints than solely myocardial infarction. CHD deaths also resulted from unstable angina pectoris or unremitting chest pain unconfirmed by autopsy, sudden lethal cardiac dysrhythmias or cardiac failure, or sudden cardiac death (with no other explanation offered) (21). Later meta-analyses related sudden cardiac death to the high dose of hydrochlorothiazide (or its equivalents) employed with minimal use of potassium or potassium-sparing agents to prevent hypokalemia (22). Thus, in these early trials, the daily dose of the thiazides or their congeners was equivalent to $100 \mathrm{mg}$ (or more) hydrochlorothiazide. Subsequent national recommendations advocated reduction of the initial thiazide dose to 12.5 or $25 \mathrm{mg}$ with a possible subsequent increase to $50 \mathrm{mg}$ as the full dose. Indeed, this recommendation has persisted in the United States and elsewhere $(23,24)$. Consequently, a subsequent meta-analysis involving elderly hypertensive patients (a population certainly with higher predisposition to CHD deaths) demonstrated 
the precise reduction in CHD that was originally predicted $(26 \%)$ and deaths from stroke were reduced by $40 \%$ (25). Hence, the issue asserting that diuretic and beta-adrenergic inhibition therapy "fails" to protect from CHD seems moot at this time.

\section{Left ventricular hypertrophy}

The Framingham Heart and other prospective epidemiological studies have repeatedly demonstrated that $\mathrm{LVH}$ is a major cardiovascular risk factor that is independent of height of arterial pressure (26). Many experimental and clinical studies have reported reduced LV mass and ventricular wall thicknesses resulting from antihypertensive therapy or, for that matter, from treatment with any antihypertensive agent if employed for a sufficiently long period of time (3). However, no prospective study has demonstrated that the reduced LV mass provides a proportionate reduction in risk from $\mathrm{LVH}$. Moreover, no clinical study has demonstrated that the so-called "regression" of LVH is synonymous with actual reduced myocardial hypertrophy although several metaanalyses have suggested that certain classes of antihypertensive agents are more effective than others in promoting $\mathrm{LVH}$ regression (27). These analyses have been flawed by inherent clinical, demographic, biological, or pharmacological variables, including patients of dissimilar gender, race, age, or number, and long-term treatment histories. Moreover, the patients were treated over varying time periods using dissimilar doses of different compounds within the same therapeutic class (which may have dissimilar physiological, pharmacodynamic or pharmacokinetic actions). In this respect, we do not know whether the biochemical or physiological changes induced directly or indirectly by prior pharmacological therapies may have been induced by biologically altered cellular "memory" (28). Finally, it is clearly possible that certain drug classes may be more effective than others in reversing clinical indices of LVH, but, at this time, it is too premature to conclude that any drug (or class of drugs) is more effective than others in reducing risk from $\mathrm{LVH}$.

\section{Coronary insufficiency}

\section{Coronary flow and flow reserve}

Resting coronary blood flow may be normal in experimental models of hypertension as well as in hypertensive patients, even in the presence of LVH. The increased total peripheral resistance in hypertension is shared by all organ circulations including the coronary one. Consequently, Marcus and associates (8) introduced the concept of coronary flow reserve which has been extremely useful to explain coronary insufficiency and silent ischemia associated with hypertensive heart disease (HHD) and other cardiovascular diseases $(8-10,29)$. Using this innovation, coronary blood flow is measured before and after physiological (e.g., exercise, ventricular pacing) or pharmacological (e.g., carbochrome, papaverine, dipyridamole, adenosine) interventions, and the difference between the two coronary blood flow and vascular resistance measurements provides an excellent index of coronary flow reserve and minimal coronary vascular resistance. These hemodynamic indices have been extremely useful in explaining the phenomena of silent ischemia, "microvascular angina", or other clinical endpoints of HHD, especially when occlusive atherosclerotic epicardial coronary arterial disease is not present. Thus, it is possible to assess hemodynamic impairment and the effect of therapy on improving flow reserve in experimental (30) and clinical hypertension (10,31). Thus, significant physiological improvement was demonstrated in the spontaneously hypertensive rat (SHR) treated with either an ACE inhibitor, an angiotensin II (type 1) receptor (AT1) antagonist, or both (in studies de- 
signed to produce equivalent reductions in arterial pressure with each of these treatment options) $(30,31)$. This hemodynamic response can be explained by coronary vasodilation produced by inhibition of angiotensin II mediated constriction by ACE inhibition, further inhibition of additionally generated angiotensin II by intracardiac chymase (32), augmented bradykinin-induced vasodilation induced by the ACE inhibitor (33), and the beneficial effect of locally produced nitric oxide.

\section{Endothelial dysfunction}

The concept of endothelial dysfunction provides an important pathophysiological mechanism underlying hypertensive cardiovascular and related complicating co-morbid disorders in experimental (34) and clinical (12-14) hypertension. Other risk factors, diseases, and clinical conditions which have been shown to be associated with endothelial dysfunction are aging, menopause, tobacco abuse, diabetes mellitus, hyperlipidemia, atherosclerosis, hyperhomocystinemia, vessel injury, and cardiac failure (35). Intrinsic to this abnormality is impaired synthesis of nitric oxide from its amino acid precursor L-arginine by the endothelium of the coronary vasculature and myocytes in hypertension (36).

Much ongoing work is directed towards defining the underlying potential mechanisms including nitric oxide synthase gene defect, increased symmetrical dimethylarginine, augmented participation (i.e., autocrine, paracrine or intracrine) of the local reninangiotensin, bradykinin-kinin or prostaglandin systems, and participation of other local peptides (e.g., endothelin). Thus, it is well known that angiotensin II and bradykinin inhibit or stimulate endothelial nitric oxide synthesis (37).

Recent experimental observations have demonstrated that ACE or AT receptor inhibition reduces LV mass and improves LV coronary flow reserve (38). These findings support the concept that local endothelial production of nitric oxide synthesis and endothelial dysfunction of the coronary circulation are thereby augmented. In addition, we have also reported that $\mathrm{L}$-arginine administration also improves intracoronary hemodynamics and other pathophysiological alterations induced by hypertensive coronary vascular disease (39). Moreover, recent clinical studies have also shown that prolonged L-arginine treatment of patients with hypertensive or atherosclerotic vascular disease improves the associated clinical and hemodynamic alterations (40).

\section{Ventricular fibrosis: diastolic dysfunction and cardiac failure}

\section{Epidemiological information}

The earliest and most recent Framingham Heart Study reports concerning prevalence of congestive heart failure have clearly shown that hypertension remains as the most common cause of cardiac failure $(41,42)$. In earlier years, hypertensive heart failure resulted primarily from impaired systolic function (43). Thus, development of LVH provided a structural and functional adaptation to the progressively increasing LV afterload of systemic hypertension (44). Indeed, the earlier antihypertensive drug studies demonstrated protection against cardiac failure $(21,45)$. However, in more recent years cardiac failure has been manifested more frequently by diastolic dysfunction, occurring primarily in elderly hypertensive patients $(42,46,47)$. Indeed, it occurs particularly in those patients with HHD having reduced coronary flow reserve (with or without associated occlusive atherosclerotic coronary artery disease) $(23,47)$. These patients also have silent ischemia, are potential victims of sudden death and left ventricular failure $(7,47)$ and account for the most common diagnosis reported in hospitalized patients over 65 years of age (23). 


\section{Ventricular fibrosis}

One important feature clearly related to $\mathrm{LVH}$, but which is unrelated to physiological hypertrophy (48), is collagen deposition and ventricular fibrosis $(19,49,50)$. This ventricular alteration in hypertensive heart disease is well established $(18,19)$, although it had been relatively neglected until recently. LV collagen deposition is increased not only in hypertension, but also with aging. Thus, our recent studies in the SHR and normotensive WKY rats of increasing ages have shed new light on LV coronary hemodynamics and associated fibrosing alterations. These studies have demonstrated progressive reduction in both LV and right ventricular (RV) coronary blood flow and flow reserve with advancing age from 23 to 80 weeks in both hypertensive and older normotensive WKY rats that was associated with increased collagen (i.e., hydroxyproline) deposition in both ventricles (51). These structural changes in SHR have been confirmed by others (50) and in patients with essential hypertension in whom hypertrophied myocytes were directly correlated with the magnitude of $\mathrm{LV}$ fibrosis (52). Most notably, these hemodynamic and structural changes associated with aging and with hypertension are neither fixed not uncorrectable therapeutically. Thus, from our earliest work LV mass has been shown to be reduced within three weeks by most antihypertensive agents in both SHR and in patients with essential hypertension (30, 53-58). It is notable that, associated with ACE inhibitor- or calcium antagonist-induced reductions in $\mathrm{LV}$ muscle mass, there was a concomitant reduction in LV collagen; however, all calcium antagonists increased RV collagen (59) as mass or wall thickness increased $(56,58,59)$. However, when an ACE inhibitor was administered with a calcium antagonist, the increased $\mathrm{RV}$ mass resulting from collagen deposition in SHR was prevented even though LV mass diminished no further (59). Hence, the RV mass increase associated with calcium antagonists was related to increased RV collagen. Finally, in one recent study, Varo et al. (50) reported that an AT1 receptor antagonist decreased post-transcriptional synthesis of fibril-forming collagen type 1 molecules in young SHR, suggesting its ability to reduce LV fibrosis.

We have recently reported increased coronary flow reserve and diminished left ventricular hydroxyproline associated with reduction in arterial pressure, LV afterload, and LV mass following treatment with an ACE inhibitor or an AT receptor antagonist (alone or in combination) (38). We have also observed similar decreases in arterial pressure, total peripheral resistance, LV mass and collagen following prolonged L-arginine treatment, although RV collagen was not as decreased (39). These LV structural and functional improvements with L-arginine were observed only in SHR, suggesting that these endothelial dysfunctional changes in response to L-arginine were more related to hypertension than to aging. However, we must emphasize that all antihypertensive drug classes have reduced LV (and, occasionally RV) mass and, not infrequently, a fact also observed with certain agents in normotensive rats. Hence, the mechanisms involved require much further biochemical and biological study and should not be ascribed simply to "regression" of LVH.

\section{Cardiac failure}

A recent report from the Framingham Heart Study found a significant reduction in the prevalence of hypertension associated with a concomitant decrease in the prevalence of severely elevated pressures and LVH (60). A cause-effect relationship for these associations might seem to be logical; however, rather than concluding that reduction of arterial pressure diminished the prevalence of $\mathrm{LVH}$, it is also possible to propose that the diminished prevalence of LV may be 
related to increased recognition and treatment of diminished hypertension, thereby preventing development of LVH. Thus, as we suggested in an earlier report on $\mathrm{LVH}$ prevention, early recognition and prompt treatment of hypertensive patients can prevent $\mathrm{LVH}$ development and, perhaps, the risk associated with LVH (2). However, once $\mathrm{LVH}$ is recognized in a hypertensive patient, effective control of pressure will prevent cardiac failure and cardiac dysrhythmias (provided that prevention of electrolyte abnormalities is carefully performed). In addition, agents that improve coronary flow and flow reserve (and reduce $L V$ fibrosis) may further reduce risk.

Several years ago we reported that increased dietary salt intake (in SHR) elevated LV mass even though lesser amounts of salt excess did not produce the hemodynamic effects of greater amounts (61). More recently, Yu et al. (62) demonstrated with a similar degree of salt excess in rats that increased LV mass is associated with severe ventricular and perivascular fibrosis of the coronary and renal circulations in the rat. These findings are particularly pertinent in terms of our emerging concepts of HHD, sudden cardiac death, congestive heart failure and, perhaps, even with respect to the increasing incidence of end-stage renal disease in patients with hypertension in recent years (23).

\section{Concluding hypothesis}

Despite the continuing reduction in morbidity and mortality due to stroke and CHD associated with hypertension, there have been persistent increases in morbidity and mortality associated with congestive heart failureand LVH-related risk. The major underlying pathophysiological mechanisms associated with LVH risk appear to be progressively impaired intracoronary hemodynamics associated and a remarkable deposition of collagen on the ventricular wall and around the coronary vessels. These LV alterations in hypertension also involve the right ventricle and may be exacerbated by aging and excessive dietary salt intake. These structural changes, together with impaired left (and right) ventricular blood flow reserves, further increase LV mass and the overall risk associated with $\mathrm{LVH}$, which is not solely the result of LV muscle hypertrophy. The increased LV mass and wall thickness are also associated with collagen deposition within the ventricular wall and the coronary vessels. These functional and structural ventricular alterations are usually recognized as electrocardiographic and echocardiographic LVH and may be manifested clinically by angina pectoris, cardiac dysrhythmias, systolic or diastolic dysfunction and cardiac failure as well as by "silent ischemia", myocardial infarction, and, of course, sudden cardiac death.

\section{References}

1. Frohlich ED (1988). The First Irvine H. Page Lecture: The mosaic of hypertension: Past, present, and future. J ournal of Hypertension, 6: S2-S11.

2. Frohlich ED (1991). Is reversal of left ventricular hypertrophy in hypertension beneficial? Hypertension, 18 (Suppl I): 133138.

3 Frohlich ED, Apstein C, Chobanian AV, Devereux RB, Dustan HP, Dzau V, FauadTarazi F, Horan MJ , Marcus M, Massie B, Pfeffer MA, Re RN, Roccella EJ , Savage $D \&$ Shub C (1992). The heart in hyperten- sion. New England J ournal of Medicine, 327: 998-1008.

4. Pauletto $P$, Libera LD, Chem D, Vescovo G, Scannapieco G, Angelini A, Pessina AC $\&$ Palu CD (1985). Propranolol-induced changes in ventricular isomyosin composition in the rat. American Heart J ournal, 109: 1269-1273.

5. Pringle SD, Dunn FG, McFarlane PW, McKillop J H, Lorimet AR \& Cobbe SM (1992). Significance of ventricular arrhythmias in systemic hypertension with left ventricular hypertrophy. American J our- nal of Cardiology, 69: 913-917.

6. Dunn FG \& Pringle SD (1993). Sudden cardiac death, ventricular arrhythmias and hypertensive left ventricular hypertrophy. J ournal of Hypertension, 11: 1003-1010.

7. Haider AN, Larson MG, Benjamin EJ \& Levy D (1998). Increased left ventricular mass and hypertrophy are associated with increased risk for sudden death. J ournal of the American College of Cardiology, 32: 1454-1459.

8. Marcus ML, Duty DB, Hiratska LF, Wright CB \& Eustham CL (1982). Decreased cor- 
onary reserve: A mechanism for angina pectoris in patients with aortic stenosis and normal coronary arteries. New England J oumal of Medicine, 307: 1362-1367.

9. Opherk D, Nall G, Zebe H, Schwarz F, Weihe E, Manthy E \& Kubler W (1984). Reduction of coronary reserve: A mechanism for angina pectoris in patients with arterial hypertension and normal coronary arteries. Circulation, 69: 1-7.

10. Scheler $S$, Wolfgang $M \&$ Strauer $B E$ (1994). Mechanisms of angina pectoris with essential hypertension and normal epicardial arteries by arteriogram. American J ournal of Cardiology, 73: 478-482.

11. Hamada M, Kuwahara T, Shigamatsu Y, Kodama K, Hara Y, Hashida H, Ikeda S, Ohstuka T, Nakata S \& Hiwada K (1998). Relation between coronary blood flow and left ventricular mass in hypertension: Noninvasive quantification of coronary blood flow by thallium-201 myocardial scintigraphy. Hypertension Research, 21: 227-234.

12. Panza J A, Quyyami AA, Brush J J JE \& Epstein SE (1990). Abnormal endothelium-dependent vascular relaxation in patients with essential hypertension. New England J ournal of Medicine, 323: 22-27.

13. Motz W, Vogt M, Rabenau D, Scheler S, Luokoff A \& Strauer BD (1991). Evidence of endothelial dysfunction in coronary resistance vessels in patients with angina pectoris and normal coronary angiograms. American J ournal of Cardiology, 68: 996-1003.

14. Treasure CB, Klein J C, Vita J A, Manoukian StV, Renwick GH, Selwin AP, Ganz P \& Alexander RW (1993). Hypertension and left ventricular hypertrophy are associated with impaired endothelium-mediated relaxation in human coronary artery resistance vessels. Circulation, 87: 86-93.

15. Mulvany MJ (1992). Vascular growth in hypertension. J ournal of Cardiovascular Pharmacology, 22: 7-11.

16. Nixenberg A \& Antony I (1996). Epicardial coronary arteries are not adequately sized in hypertensive patients. J ournal of the American College of Cardiology, 27: 1115-1123.

17. Chrysant SG, Frohlich ED, Adamopoulos PN, Stein PD, Whitcomb WH, Allen EW \& Neller G (1976). Pathophysiological significance of "stress" or relative polycythemia in essential hypertension. American J ournal of Cardiology, 37: 1069-1072.

18. Huysman J AN, Viegen HW, Vankerlaarse A \& Eulderink F (1989). Changes in nonmyocyte tissue composition associated with pressure overload of hypertrophied human hearts. Pathology, Research and Practice, 184: 577-581.

19. Weber KT, Sun Y \& Guarda E (1994). Structural remodeling in hypertensive heart disease and the role of hormones. Hypertension, 23: 869-877.

20. Varo N, Etayo J C, Zalba G, Beaumont J, Iraburu MJ , Montiel C, Gil MJ , Monreal I \& Diez J (1999). Losartan inhibits the post-transcriptional synthesis of collagen type 1 and reverses left ventricular fibrosis in spontaneously hypertensive rats. J ournal of Hypertension, 17: 107-114.

21. Collins $C$, Peto $R, M$ acMahon $S$, Hebert $P$, Fiebach NH, Eberlein KA, Godwin J, Qizilbash N, Taylor J O \& Hennekens CH (1990). Blood pressure, stroke and coronary heart disease. Part II. Short-term reductions in blood pressure: overview of randomised drug trials in their epidemiological context. Lancet, 335: 827-838.

22. Siscovick DS, Raghunthan TE, Psaty BM, Koepsell TD, Wicklund KG, Lin X, Cobb L, Rautaharju PM, Copass MK \& Wagner EH (1994). Diuretic therapy for hypertension and the risk of primary cardiac arrest. New England J ournal of Medicine, 330: 1852-1857.

23. J oint National Committee on Prevention, Detection, Evaluation, and Treatment of High Blood Pressure (1997). The Sixth Report of the J oint National Committee (J NC-VI) on Prevention, Detection, Evaluation, and Treatment of High Blood Pressure. Archives of Internal Medicine, 157: 2413-2446.

24. Swales J D (1994). Guidelines for treating hypertension. In: Swales J D (Editor), Textbook of Hypertension. Blackwell Scientific Publications, Oxford, 1190-1221.

25. Thijs L, Fagard R, Lijuen F, Staessen J, Van Hoof R \& Amery A (1992). A metaanalysis of outcome trials in elderly hypertensives. J ournal of Hypertension, 10: 1103-1109.

26. Kannel WB, Gordon T \& Offut D (1969). Left ventricular hypertrophy by electrocardiogram: prevalence, incidence and mortality in the Framingham Study. Annals of Internal Medicine, 71: 99-105.

27. Schmieder RE, Martus $P \&$ Lkingbeil $A$ (1996). Reversal of left ventricular hypertrophy in essential hypertension: A metaanalysis of randomized double-blind studies. J ournal of the American Medical Association, 275: 1507-1513.

28. Re RN (1999). Hypothesis: The nature of intracrine peptide hormone action. Hypertension, 34: 534-538.

29. Pringle SD, Dunn FD, Tweddel AC, Martin W, MacFarlane PW, McKillopJ H, Lorimer AR \& Cobbe SM (1992). Symptomatic and silent myocardial ischemia in hypertensive patients with left ventricular hypertrophy. British HeartJ ournal, 67: 377-382.

30. Nunez E, Hosoya K, Susic D \& Frohlich ED (1997). Enalapril and losartan reduced cardiac mass and improved coronary hemodynamics in SHR. Hypertension, 29: 519-524.

31. Metz W \& Strauer BE (1996). Improvement of coronary flow reserve after long-term therapy with enalapril. Hypertension, 27: 1031-1038.

32. Balcells $E$, Meng QC, J ohnson J r WWH, Oparil S \& Dell'Halia LJ (1997). Angiotensin II formation from ACE and chymase in human and animal hearts: Methods and species considerations. American J ournal of Physiology, 273: H1769-H1774.

33. Linz W, Wiemer G, Golke P, Unger T \& Sholkens BA (1995). Contribution of kinins on the cardiovascular action of angiotensin converting enzyme inhibitors. Pharmacological Reviews, 47: 25-29.

34. Frohlich ED (1997). Arthur C. Corcoran Memorial Lecture: Influence of nitric oxide and angiotensin II on renal involvement in hypertension. Hypertension, 29: 188-193.

35. Luscher TF (1994). The endothelium in hypertension: bystander, target or mediator? J ournal of Hypertension, 12: 105-116.

36. Zeiher AM, Drexler H, Saurbrier B \& J ust H (1993). Endothelium-mediated coronary blood flow modulation in humans. Effects of age, atherosclerosis, hypercholesterolemia, and hypertension. J ournal of Clinical Investigation, 92: 652-662.

37. Anniken B-O, Holte HR \& Berg T (1997). Amplification of kinin-induced hypertension by nitric oxide synthesis in spontaneously hypertensive rats. Hypertension, 29: 53-57.

38. Susic D \& Frohlich ED (1999). Pharmacologic agents on cardiovascular mass and coronary hemodynamics in aging spontaneously hypertensive rats. J ournal of $\mathrm{Hy}-$ pertension, 17: 1-7.

39. Susic D, Francischetti $A \&$ Frohlich ED (1999). Prolonged L-arginine on cardiovascular mass and myocardial hemodynamics and collagen in aged spontaneously hypertensive rats and normal rats. Hypertension, 33: 451-455.

40. Bottchen M, Botker HE, Sonne H, Nielsen TT \& Czernin J (1999). Endothelium-dependent and -independent perfusion reserve and the effect of L-arginine on myocardial perfusion in patients with syndrome X. Circulation, 99: 1795-1801.

41. McKee PA, Castelli WP, McNamara OM \& Kannel WB (1971). The natural history 
of congestive heart failure. The Framingham Heart Study. New England J ournal of Medicine, 285: 1441-1446.

42. Vasan RS, Benjamin EJ \& Levy D (1995). Prevalence, clinical features and prognosis of diastolic heart failure: An epidemiologic perspective. J ournal of the American College of Cardiology, 26: 1565-1574.

43. Frohlich ED, Tarazi RC \& Dustan HP (1971). Clinical-physiological correlations in the development of hypertensive heart disease. Circulation, 44: 446-455.

44. Pfeffer MA, Pfeffer JM \& Frohlich ED (1976). Pumping ability of the hypertrophying left ventricle of the spontaneously hypertensive rat. Circulation Research, 38: 423-429.

45. MacMahon SW, Cutler J A, Furberg CD \& Payne GH (1989). The effects of drug treatment on morbidity and mortality from cardiovascular disease: a review of randomized controlled trials. Progress in Cardiovascular Diseases, 29: 99-118.

46. Topol EJ , Traill TA \& Fortuin NJ (1985). Hypertensive hypertrophic cardiomyopathy of the elderly. New England J ournal of Medicine, 312: 277-283.

47. Vasan RS \& Levy D (1996). The role of hypertension in the pathogenesis of heart failure: A clinical mechanistic overview. Archives of Internal Medicine, 156: 1789-1796.

48. Shapiro LM \& McKenna WJ (1984). Left ventricular hypertrophy relation of structure to diastolic function in hypertension. British Heart J ournal, 51: 637-642.

49. Caspari PG, Newcomb M, Gibson K \&
Harris P (1977). Collagen in the normal and hypertrophied ventricle. Cardiovascular Research, 11: 554-558.

50. Susic D, Nunez E, Hosoya K \& Frohlich ED (1998). Coronary hemodynamics in aging spontaneously hypertensive (SHR) and normotensive Wistar-Kyoto (WKY) rats. J ournal of Hypertension, 16: 231-237.

51. Rossi MA (1998). Pathologic fibrosis and connective tissue matrix in left ventricular hypertrophy due to chronic arterial hypertension in humans. J oumal of Hypertension, 16: 1031-1041.

52. Pegram BL, Ishise $S \&$ Frohlich ED (1982). Effect of methyldopa, clonidine, and hydralazine on cardiac mass and haemodynamics in Wistar Kyoto and spontaneously hypertensive rats. Cardiovascular Research, 16: 40-46.

53. Dunn FG, Ventura HO, Messerli FH, Kobrin I \& Frohlich ED (1987). Time course of regression of left ventricular hypertrophy in hypertensive patients treated with atenolol. Circulation, 76: 254-258.

54. Amodeo C, Kobrin I, Ventura HO, Messerli FH \& Frohlich ED (1986). Immediate and short-term hemodynamic effects of diltiazem in patients with hypertension. Circulation, 73: 108-113.

55. Frohlich ED, Sasaki O, Chien $Y \& \&$ Arita M (1992). Changes in cardiovascular mass, left ventricular pumping ability, and aortic distensibility after calcium antagonist in Wistar-Kyoto and spontaneously hypertensive rats. J ournal of Hypertension, 10 : 1369-1378.

56. Dunn FG, Oigman W, Ventura HO,
Messerli FH, Kobrin I \& Frohlich ED (1984). Enalapril improves systemic and renal hemodynamics and allows regression of left ventricular mass in essential hypertension. American J ournal of Cardiology, 53: 105-108.

57. Aristizabal D, Messerli FH \& Frohlich ED (1994). Disparate structural effects of left and right ventricles by angiotensin converting enzyme inhibitors and calcium antagonists. American J ournal of Cardiology, 73: 483-487.

58. Arita M, Horinaka S, Komatsu K \& Frohlich ED (1993). Reversal of left ventricular hypertrophy with different classes of drugs causes differing ventricular biochemical changes. J ournal of Hypertension, 11: S354-S355.

59. Mostero A, D'Agostino RB, Silbershatz $H$, Sytkowski PA, Kannel WB, Gobbee DE \& Levy $D$ (1999). Trends in the prevalence of hypertension, antihypertensive therapy, and left ventricular hypertrophy from 1950 to 1989. New England J ournal of Medicine, 340: 1221-1227.

60. Frohlich ED, Chien Y, Sesoko S \& Pegram BL (1993). Relationships between dietary sodium intake, hemodynamics and cardiac mass in spontaneously hypertensive and normotensive Wistar-Kyoto rats. American J ournal of Physiology, 264: R30-R34.

61. Yu HCM, Burrell LM, Black MJ, Wu LL, Dilley RJ, Cooper ME \& J ohnston $\mathrm{Cl}$ (1998). Salt induces myocardial and renal fibrosis in normotensive and hypertensive rats. Circulation, 98: 2621-2628. 